\title{
Araneísmo em equino da Escola de Equitação do Exército
}

Carine Rodrigues Pereira ${ }^{[a]}$, Bruna Machado Amaral Rosa ${ }^{[b]}$, Daniela Cristina Matoso e Silva ${ }^{[b]}$, Vanessa Costa de Lima $a^{[b]}$

\footnotetext{
[a] Universidade Federal de Lavras (UFLA), Itauna, MG, Brasil

${ }^{[b]}$ Escola de Equitação do Exército, Rio de Janeiro, RJ, Brasil
}

*Autor correspondente

e-mail: rpcarine@gmail.com

\section{Resumo}

No Brasil, os acidentes causados por aranhas, denominados araneísmo, são provocados principalmente por três gêneros: Phoneutria (armadeira), Loxosceles (aranha-marrom) e Latrodectus (viúva-negra). No acidente com aranhas do gênero Phoneutria há dor, edema, parestesia e sudorese. Já a lesão cutânea do loxoscelismo caracteriza-se por eritema e edema, dor, febre, equimose, palidez (placa marmórea) e necrose seca ulcerada de difícil cicatrização. 0 componente mais importante do veneno é a enzima esfingomielinase $\mathrm{D}$, que atua sobre as membranas celulares, gerando ativação das cascatas do sistema complemento, coagulação e plaquetas, provocando intensa reação inflamatória local acompanhada de edema, hemorragia e necrose focal. A forma cutânea visceral do loxoscelismo é rara, com hemólise intravascular e insuficiência renal aguda. No latrodectismo há dor, sudorese, ptose e contraturas musculares. Um equino com alto desempenho na modalidade salto, de propriedade do Exército Brasileiro e estabulado em baia na Escola de Equitação do Exército, apresentou um quadro clínico de dor caracterizado por sudorese, frequência cardíaca de 70 bpm, claudicação grau 4, edema no membro pélvico direito (MPD) na articulação metatarsofalangeana e pico febril de $40^{\circ} \mathrm{C}$. Após dois dias de tratamento, ocorreu uma fistulação na face plantado-lateral da articulação metatarsofalangeana do MPD com conteúdo sero-sanguinolento. 0 tratamento adotado preconizava a limpeza das feridas e remoção do tecido morto diariamente, além de alternâncias e combinações entre Flunixin Meglumine, Fenilbutazona, $1,1 \mathrm{mg} / \mathrm{kg}$ e Meloxicam 0,6 mg/kg por via intravenosa (IV), duas vezes ao dia (BID), durante uma semana. Também foram realizadas massagens tópicas com Dimetilsulfóxido, Dexametasona, Prednisolona e Lidocaína para otimizar a analgesia e absorção dos medicamentos. Utilizouse o Omeprazol a fim de evitar úlceras gastrointestinais. 0 tratamento com antibióticos foi à base de Estreptomicina e Penicilinas Procaína e Benzatina 8.000 UI/kg IV uma vez ao dia (SID) nos três primeiros 
dias, sem evolução significativa. Nos dez dias seguintes, utilizou-se Sulfonamida e Trimetoprina $13 \mathrm{mg} / \mathrm{kg}$ IV SID, concomitante à lavagem da ferida com Clorexidine, solução de Gentamicina a 10\% e aplicação de pomada à base de Sulfato de Gentamicina, Sulfanilamida, Sulfadiazina, Uréia e Vitamina A. No vigésimo dia, todo o espaço morto causado pela necrose já havia sido preenchido por tecido de granulação e fibrina. Um mês após a fistulação, o animal começou a ser exercitado novamente em caminhadas diárias de 15 minutos com ligas de proteção. 0 diagnóstico de loxoscelismo foi realizado clinicamente por meio dos sintomas e características das lesões de aspecto necrótico com áreas pálidas desvitalizadas, mescladas às áreas isquêmicas e posteriormente ulcerativas e secas. Não foi utilizada nenhuma técnica diagnóstica de imagem. 0 tratamento foi realizado durante 145 dias até total cicatrização da ferida. Atualmente, o equino participa de competições de salto sem apresentar sequelas decorrentes do araneísmo. 0 diagnóstico definitivo é realizado pela detecção do veneno no soro do animal através do método ELISA, com elevada especificidade e sensibilidade, porém pouco utilizado na rotina clínica. Apesar da recuperação satisfatória do equino, o prognóstico ao início do tratamento era reservado pela importância da região anatômica atingida pela picada, em que estruturas nobres como tendões e ligamentos poderiam ser acometidas e comprometer a recuperação do animal. 0 soro antiaracnídico tem sua eficácia reduzida após 36 horas da inoculação do veneno e devido à dificuldade de se diagnosticar o araneísmo em equinos dentro deste período, esta alternativa de tratamento não é comumente utilizada. Com base nos resultados obtidos, sugere-se o uso de antibióticos de amplo espectro, antiinflamatórios não esteroidais, remoção do tecido morto e limpeza diária das feridas como tratamento de escolha nos casos de loxoscelismo.

Palavras-chave: Araneísmo. Loxoscelismo. Loxosceles sp. 